\title{
Blickdiagnose
}

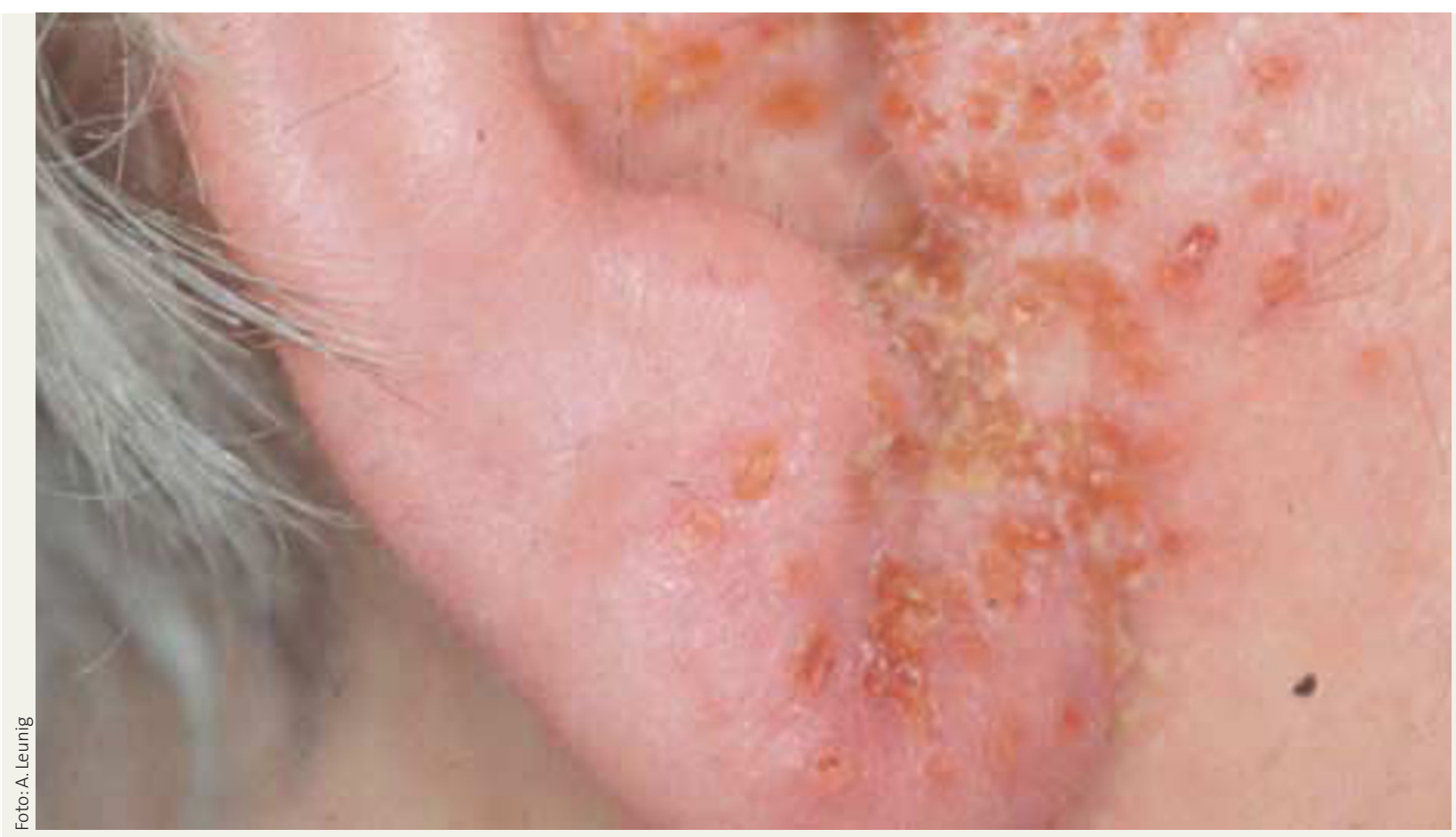

\section{Schmerzhafte Bläschen am Ohr}

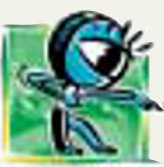

Eine 41-jährige Patientin kam in die Sprechstunde und berichtete über das Auftreten einer Rötung im Bereich der Ohrmuschel, begleitet von Bläschen und neuralgiformen Schmerzen. Zusätzlich bestehe ein allgemeines Krankheitsgefühl und Fieber.

Klinisch liegt das typische Erscheinungsbild eines Zoster oticus vor. Dieser ist neben dem Zoster ophthalmicus die häufigste Lokalisation einer Herpes-simplex- bzw. Varicella-Zoster-Virusinfektion im Kopfbereich. Dabei werden Varicella-Zoster-Viren in den Ganglienzellen des VII. und VIII. Hirnnerven reaktiviert. Begleitend können eine periphere Fazialisparese, hochgradige retrocochleäre Schwerhörigkeit bis Ertaubung, Schwindel und Gleichgewichtsstörungen auftreten. Diagnostisch ist neben der Inspektion der otoskopische Befund mit Bläschen auf der Ohrmuschel, dem Gehörgang und dem Trommelfell wegweisend. Eine Hörund Gleichgewichtsuntersuchung sollten zum Ausschluss einer retrocochleären Hör- und Gleichgewichtsstörung durchgeführt werden. Die Funktionsprüfung der Nn. facialis, glossopharyngeus und vagus gibt Hinweise auf eine mögliche Mitbeteiligung dieser Hirnnerven.

Die Therapie besteht in der Gabe von Aciclovir, Glukokortikoiden, Analgetika sowie bei starkem Schwindel von Antivertiginosa. Die lokalen Effloreszenzen sollten steril abgedeckt werden; zur Vermeidung einer bakteriellen Superinfektion sollte eine orale Antibiose erfolgen.

Nicht selten kommt es zu bleibenden Fazialisparesen. Ertaubungen und Gleichgewichtsstörungen sind meist irreversibel, geringfügige Hör- und Gleichgewichtsstörungen können sich zurückbilden. Die neuralgiformen Schmerzen halten möglicherweise monatelang an.

- Priv.-Doz. Dr. med. Andreas Leunig, Oberarzt, Klinik und Poliklinik für Hals-Nasen-Ohren-Heilkunde der Ludwig-Maximilians-Universität München

\section{Ihr besonderer Fall?}

Sicher sehen auch Sie ab und an einen besonders eindrucksvollen Befund in Ihrer Praxis. Fotografieren Sie ihn, schreiben Sie uns unter dem Stichwort Blickdiagnose, bei Veröffentlichung erhalten Sie 100 Euro.

MMW-Fortschritte der Medizin

E-Mail: manhart@urban-vogel.de

Fax: 089/4372-1420

Weitere interessante Blickdiagnosen finden Sie in unserem Online-Archiv unter www.mmw.de. 